\title{
Improving Skin Aging, Skin Hydration and Sensitive Skin with Four Specific Skin Care Products: Results from a Single-Centre, Observational, Prospective Study
}

\author{
Antonella Piccioni' ${ }^{1}$, Carlota Gutiérrez García-Rodrigo ${ }^{1}$, Cristina Pellegrini ${ }^{1}$, \\ Giampiero Mazzocchetti ${ }^{2}$, Maria Concetta Fargnoli ${ }^{*}$ \\ ${ }^{1}$ Department of Dermatology, University of L'Aquila, L'Aquila, Italy \\ ${ }^{2}$ UOSDDermatology, Hospital “Santo Spirito", Pescara, Italy \\ Email: *mariaconcetta.fargnoli@univaq.it
}

How to cite this paper: Piccioni, A., GarcíaRodrigo, C.G., Pellegrini, C., Mazzocchetti, G. and Fargnoli, M.C. (2017) Improving Skin Aging, Skin Hydration and Sensitive Skin with Four Specific Skin Care Products: Results from a Single-Centre, Observational, Prospective Study. Journal of Cosmetics, Dermatological Sciences and Applications, 7, 48-56.

http://dx.doi.org/10.4236/jcdsa.2017.71005

Received: January 8, 2017

Accepted: March 4, 2017

Published: March 7, 2017

Copyright $\odot 2017$ by authors and Scientific Research Publishing Inc. This work is licensed under the Creative Commons Attribution International License (CC BY 4.0).

http://creativecommons.org/licenses/by/4.0/

\begin{abstract}
In this study, we assessed the efficacy and safety of four skin care products indicated for skin hydration (Aqua Therapy ${ }^{\circledR}$ and Perfecta ${ }^{\circledR}$ ), skin aging (Unica Resurfacing Therapy ${ }^{\circledR}$ ) and sensitive skin (Comfort Therapy ${ }^{\circledR}$ ), in four groups of 7 volunteers with different skin types. These products belong to four skin care ranges (Aqua ${ }^{\circledR}$, Perfecta $^{\circledR}$, Unica ${ }^{\circledR}$ and Comfort ${ }^{\circledR}$ ) and are formulated with a specific combination of active compounds $\left(\right.$ Dermo $\left.28^{\circledR}\right)$. Evaluation of sebum secretion, hydration and $\mathrm{pH}$ of the skin (all groups), wrinkle severity (Unica Resurfacing Therapy ${ }^{\circledR}$ ) and erythema $\left(\right.$ Comfort Therapy ${ }^{\circledR}$ ) was performed at baseline and after 4 weeks of treatment. A significant increase in hydration was recorded in subjects with dry skin receiving Aqua Therapy ${ }^{\circledR}$ for facial hydration and Perfecta ${ }^{\circledR}$ for body hydration, respectively ( $p<0.001$ for both). A significant decrease in the modified Fitzpatrick wrinkle scale $(\mathrm{p}=0.006)$ and an increase in sebum secretion and hydration $(\mathrm{p}=0.013$ and $\mathrm{p}<0.001$, respectively) were observed in the Unica Resurfacing Therapy ${ }^{\circledR}$ group. In subjects with sensitive skin $\left(\right.$ Comfort Therapy $\left.{ }^{\circledR}\right)$, a decrease in erythema $(p=$ $0.012)$, an increase in sebum secretion $(p=0.001)$ and hydration $(p<0.001)$, and a reduction in $\mathrm{pH}(\mathrm{p}=0.005)$ were detected at the end of treatment. Only one patient reported a minor adverse event. This specific combination of active ingredients was clinically effective and safe, and contributed to skin surface hydrolipidic film regeneration, improvement of wrinkle depth and reduction of redness.
\end{abstract}

\section{Keywords}

Skin Hydration, Skin Aging, Sensitive Skin 


\section{Introduction}

Maintenance of a barrier between the body and the external environment is one of the main functions of the skin. The lipid matrix of the hydrolipidic film is crucial to this, preventing excessive water and electrolyte loss, avoiding penetration of antigenic compounds from the external environment into the epidermal and dermal layers, and facilitating the transfer of antioxidants (e.g. vitamin E) to the surface of the skin [1] [2] [3]. Lipid matrix dysfunction, together with the effects of sunlight and smoking, plays indeed an important role in skin aging processes, typified by dryness, wrinkles, age spots, and impaired healing [4]. Individual skin type is determined by sebum secretion balance, hydration levels and the re-epithelialization to desquamation ratio. In older skin, the ratio may be compromised since re-epithelialization is slow, and the natural renewal process can be accelerated by "peeling" the top layer of the skin (resurfacing) [5] [6]. Different parameters such as transepidermal water loss, sebum production, elasticity and $\mathrm{pH}$ can be used to assess individual skin type [7]. Only a minority of individuals have normal skin type, which is, however, difficult to categorize specifically since normal skin characteristics vary greatly according to ambient temperature, humidity, mechanical or chemical stressors and age. Dry skin is an uncomfortable condition marked by scaling, itching and cracking. Estrogen deficiency, in addition to decreased dermal collagen levels, accentuates dry skin by reducing sebum secretion [8]. Moisturizers generally contain lipids and ingredients with emollient, humectant and occlusive properties to restore the hydration of the epidermal barrier [9]. Oily, greasy, or shiny skin can be due to an increase in sebum production, which is associated to androgen levels. Soaps and cleaners are able to solubilize and absorb oils due to their surfactant content [10]. Lastly, sensitive skin type is a consequence of hyper-reactivity, related with significant intrinsic factors such as dysfunctional vascular reaction and inflammation, leading to flushing and couperose. Moisturizers with anti-inflammatory compounds and/or antioxidants can minimize inflammatory reactions and modulate vascular reactivity [11]. Predominant normal $\mathrm{pH}$ of the skin ranges from 4.2 to 5.6 (depending on the specific area of the body), which is slightly acid, and is influenced by the composition of the hydrolipidic film of the stratum corneum [12].

Selecting the optimal moisturizer depends on skin type, vehicle, and needs of the patient. In this study, we assessed the efficacy and safety of four skin care products for skin hydration, skin aging and sensitive skin.

\section{Materials and Methods}

\subsection{Subject Selection and Treatment Procedure}

A single-centre, clinical-instrumental observational prospective study was performed at the Department of Dermatology, University of L'Aquila, Italy, from November 2015 to February 2016, to evaluate the efficacy and safety of four skin care products for skin hydration (Aqua Therapy ${ }^{\circledR}$ and Perfecta ${ }^{\circledR}$ ), skin aging 
(Unica Resurfacing Therapy ${ }^{\circledR}$ ) and sensitive skin $\left(\right.$ Comfort Therapy $\left.{ }^{\circledR}\right)$ in four groups of 7 volunteers consecutively selected among outpatients based on their skin type (dry, sensitive and photoaged skin). These products belong to four skin care ranges (Aqua ${ }^{\circledR}$, Perfecta $^{\circledR}$, Unica $^{\circledR}$ and Comfort ${ }^{\circledR}$ ) and are formulated with a specific combination of active compounds (Dermo $28^{\circledR}$ ) (Tuttestetica, Bologna, Italy).

In the first and second group all subjects had dry skin type and were given Aqua Therapy ${ }^{\circledR}$ facial hydration (Group 1) and Perfecta ${ }^{\circledR}$ body-hydration (Group 2 ), respectively. Both treatments have two phases. The first phase is a peel-lotion formulated with various natural extracts: pineapple, passion flower, Rosa Canina and Vitis Vinifera, in a mixture with glycolic acid, mandelic acid and vitamin A. It promotes cell renewal and enhances the moisturizing ability of the skin. The second phase for facial hydration is a soft emulsion that uses the Aqua-System ${ }^{\circledR}$ functional complex, composed of vitamin $\mathrm{C}$, hyaluronic acid and a hydrating component (algae extract) that, in combination with natural plant extracts, consisting of pineapple, passion flower and Vitis vinifera, insures optimum skin hydration. The second phase for body hydration contains shea butter, sweet almond, jojoba oil, beech Extract and vitamins $\mathrm{C}$ and $\mathrm{E}$.

The third group of subjects (Group 3) was treated with the two-phase treatment, Unica Resurfacing ${ }^{\circledR}$ therapy for skin aging. The first phase comprised a combination of the Bioactivating complex, thoroughly mixed with the Biodetox Powder. The second phase involved application of biovital emulgel, which stimulates collagen formation and attenuates skin spots. Both phases contain a wide range of ingredients including ascorbic, glycolic, lactic and salicylic acids, retinol and several fruit extracts that help to promote the renewal and oxygenation of the epidermis and additionally have antioxidant function.

Subjects with sensitive skin type were included in Group 4. They were treated with Comfort Therapy ${ }^{\circledR}$, that again consisted of two phases. The first phase was a peel-product, composed of a balanced synergy of alpha-hydroxyacids, retinol and pantenol, which stimulates cell renewal. The second phase was a mask that used the Comfort-System ${ }^{\circledR}$ functional complex, composed of Calendula Officinalis, Argania, ceramides, Ruscus Aculeatus and liquorice derivatives, that enhances the skin's immune defences, is soothing and reduces redness.

The four cosmeceutical products were applied weekly by a dermatologist and the home care related ranges self-re-applied by the subject daily for 4 weeks.

\subsection{Subject Evaluation}

All evaluations were carried out at baseline and after 4 weeks of application. Sebum secretion, hydration and $\mathrm{pH}$ of the skin were measured with the Derma Unit-Combi 3 digital device (G. F. Secchi, Tavernerio, Italy). Wrinkles (Group 3) were evaluated according to the modified Fitzpatrick wrinkle scale (MFWS), which scores severity of nasolabial fold wrinkling by wrinkle depth ranging from 0 to $3 \mathrm{~mm}$ [13]. Evaluation of wrinkle severity was carried out by one blinded evaluator, who was initially trained on wrinkle assessment according to the MFWS 
on a test set of patients. Erythema (Group 4) was scored on a 4-point severity scale (0: none, 1: mild, 2: moderate; 3: severe). Photographic documentation was performed using a high-resolution digital camera (Canon, USA) at a fixed distance and under standard conditions of illumination.

\subsection{Statistical Analysis}

We computed mean and standard deviations to compare tested skin parameters at baseline and after 4 weeks of treatment using Kruskal-Wallis tests, Paired t-tests and Wilcoxon, as appropriate. The statistical significance was considered at $\mathrm{p}<0.05$, Data were analyzed using the GraphPad Prism statistical package, version 5.03 .

\section{Results}

A total of 28 volunteers, 7 in each treatment group were enrolled in the study and completed the treatment period. Seven females, mean age 36 years (age range 33 - 41 years) were included in Group 1; 7 females, mean age 61.2 years (age range 57 - 66 years) in Group 2, 6 females and 1 male, mean age 57.7 years (age range 50 - 65 years) in Group 3 and 7 females, mean age 42 years (age range 29 - 51 years) in Group 4.

Table 1 summarizes results of clinical and instrumental evaluation. A significant increase in hydration was recorded in Groups 1 and 2 receiving Aqua Therapy ${ }^{\circledR}$ for facial hydration (Figure 1 ) and Perfecta ${ }^{\circledR}$ for body hydration, respectively ( $\mathrm{p}<0.001$ for both). In addition, a reduction in $\mathrm{pH}(\mathrm{p}=0.005)$ was observed in Group 1 and in sebum secretion $(\mathrm{p}=0.036)$ in Group 2.

Table 1. Results of clinical and instrumental evaluation.

\begin{tabular}{|c|c|c|c|c|}
\hline Treatment & Variable & Baseline Mean (SD) & Week 4 Mean (SD) & $\mathrm{p}$ \\
\hline \multirow{3}{*}{$\begin{array}{l}\text { Group } 1 \\
\text { Aqua Therapy }\end{array}$} & Sebum & $127.10(57.53)$ & $137.90(48.32)$ & 0.629 \\
\hline & Hydration & $32.39(3.98)$ & $47.06(0.59)$ & $<0.001$ \\
\hline & $\mathrm{pH}$ & $5.70(0.2)$ & $5.34(0.18)$ & 0.005 \\
\hline \multirow{3}{*}{$\begin{array}{l}\text { Group } 2 \\
\text { Perfecta }\end{array}$} & Sebum & $209.20(49.96)$ & $199.30(43.92)$ & 0.036 \\
\hline & Hydration & $29.64(2.79)$ & $44.44(5.60)$ & $<0.001$ \\
\hline & $\mathrm{pH}$ & $5.61(0.16)$ & $5.53(0.07)$ & 0.218 \\
\hline \multirow{4}{*}{$\begin{array}{l}\text { Group } 3 \\
\text { Unica Resurfacing } \\
\text { Therapy }{ }^{\circledR}\end{array}$} & MFWS & $1.64(0.89)$ & $1.36(0.75)$ & 0.006 \\
\hline & Sebum & $59.94(32.86)$ & $99.89(15.07)$ & 0.013 \\
\hline & Hydration & $34.30(6.13)$ & $46.40(1.28)$ & $<0.001$ \\
\hline & $\mathrm{pH}$ & $6.31(0.56)$ & $5.50(0.11)$ & 0.003 \\
\hline \multirow{4}{*}{$\begin{array}{l}\text { Group } 4 \\
\text { Comfort Therapy }\end{array}$} & Erythema & $2.43(0.53)$ & $0.86(0.86)$ & 0.012 \\
\hline & Sebum & $88.29(60.8)$ & $110.00(48.56)$ & 0.001 \\
\hline & Hydration & $34.11(5.92)$ & $48.26(5.88)$ & $<0.001$ \\
\hline & $\mathrm{pH}$ & $6.36(0.57)$ & $5.47(0.07)$ & 0.005 \\
\hline
\end{tabular}

MFWS, modified Fitzpatrick wrinkle scale. 
A significant decrease in MFWS ( $\mathrm{p}=0.006)$, an increase in sebum secretion and hydration ( $\mathrm{p}=0.013$ and $\mathrm{p}=0.001$, respectively) and a decrease in $\mathrm{pH}$ values $(\mathrm{p}=0.003)$ were observed in Group 3 (Unica Resurfacing Therapy ${ }^{\circledR}$ for skin aging) (Figure 2 and Figure 3 ).

Variations in all parameters were statistically significant in Group 4 (Comfort Therapy $^{\circledR}$ for sensitive skin), with a decrease in erythema $(p=0.012)$, an increase in sebum secretion $(\mathrm{p}=0.011)$ and hydration $(\mathrm{p}<0.001)$, and a reduction in $\mathrm{pH}$ $(\mathrm{p}=0.005)$ (Figure 4).
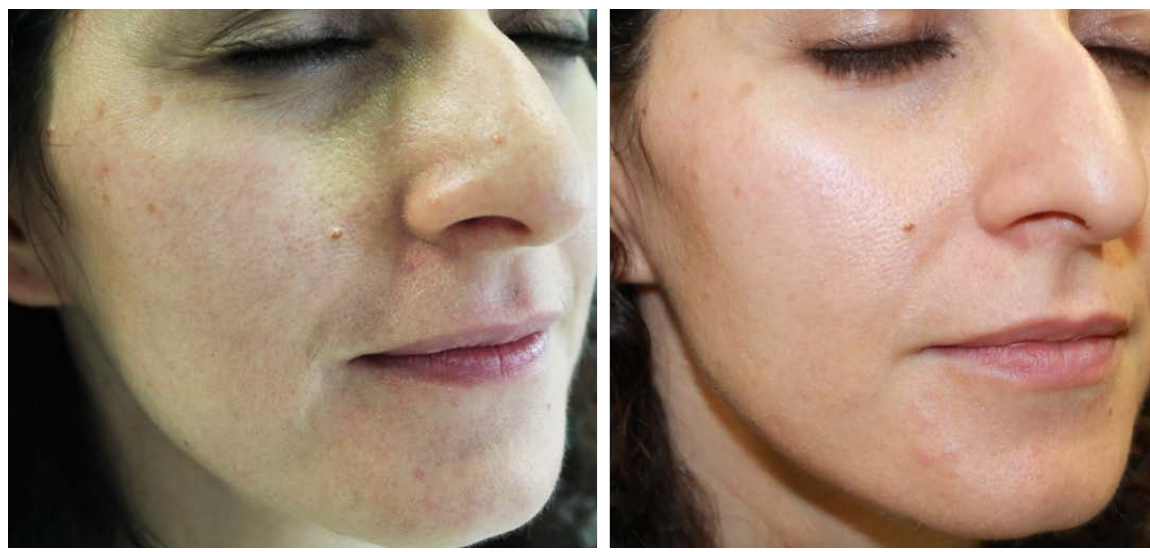

Figure 1. Baseline (left) and after 4 weeks of Aqua Therapy ${ }^{\circledR}$ application (right).
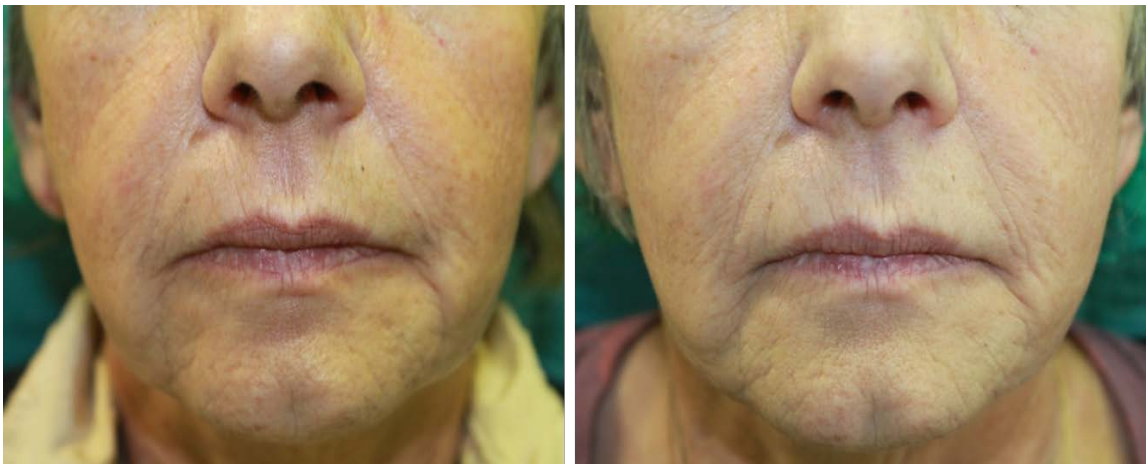

Figure 2. Baseline (left) and after 4 weeks of Unica Resurfacing Therapy ${ }^{\circledR}$ application (right).
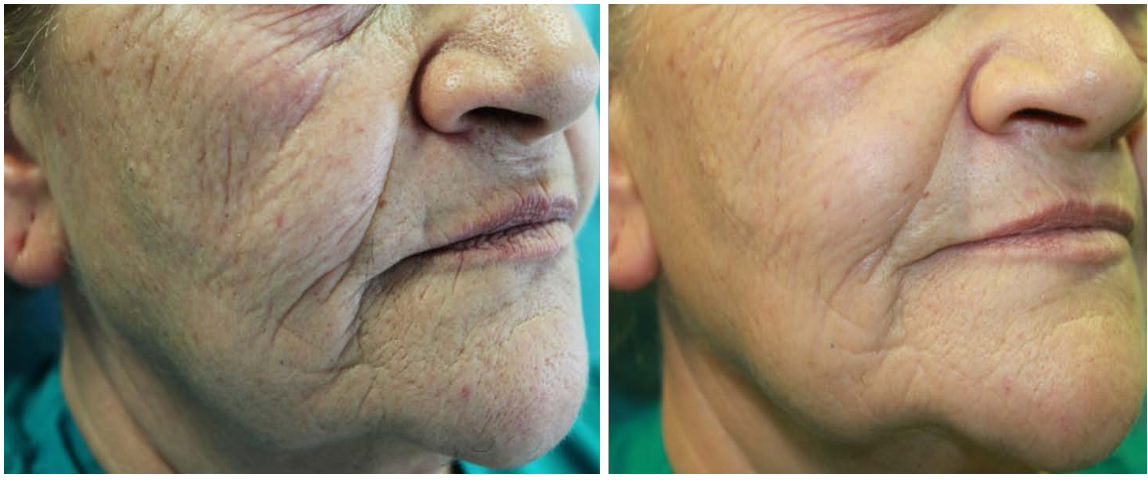

Figure 3. Baseline (left) and after 4 weeks of Unica Resurfacing Therapy ${ }^{\circledR}$ application (right). 

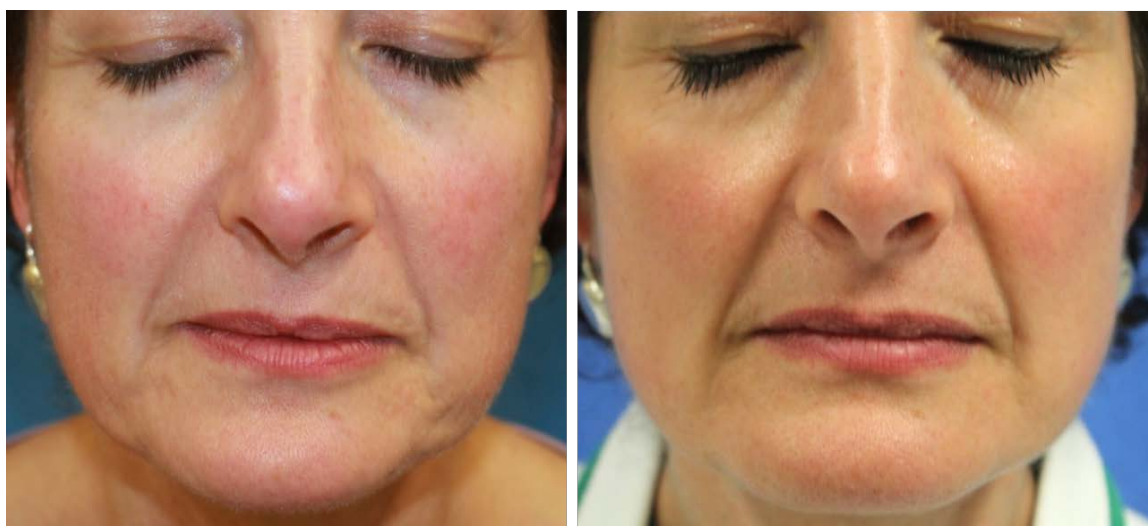

Figure 4. Baseline (left) and after 4 weeks of Comfort Therapy ${ }^{\circledR}$ application (right).

Regarding safety, a minor adverse event was reported in only one patient after the fourth week of Comfort Therapy ${ }^{\circledR}$ treatment. He developed mild itchy erythema on the eyelids, that occurred after a lengthy period of intense sun exposure and disappeared without treatment after a few days.

\section{Discussion}

Four skin care products were tested for 4 weeks in patients with different skin types with significant results. In Aqua Therapy ${ }^{\circledR}$ and Perfecta Therapy ${ }^{\circledR}$ groups of participants, there was a $50 \%$ and $30 \%$ improvement in facial and body hydration levels, respectively. An increase of $60 \%$ and $35 \%$ in sebum secretion and hydration levels together with a significant improvement in wrinkle score were observed in the group that applied Unica Resurfacing Therapy ${ }^{\circledR}$. A substantial reduction in erythema was detected in more than $50 \%$ of the subjects in the Comfort Therapy ${ }^{\circledR}$ group, with also a $25 \%$ increase of sebum secretion levels and $40 \%$ of hydration levels and a $20 \%$ reduction in $\mathrm{pH}$ value.

These four products focus on skin exfoliation and cell renewal, thanks to the combination of different ingredients, whose main molecules are Passion fruit, vitamin A and alpha-hydroxyacids, formulated in an unique delivery-system.

Passion Fruit (Passiflora edulis) is a vine species of the passion flower family, which is found in the tropical regions of America, where it is used as a medicinal herb. The anti-inflammatory [14] [15] and anxiety-reducing [16] [17] effects of the leaves, vines, and flowers of Passion fruit has already been reported and associated with its polyphenol content. However, specific polyphenols are found in the seeds, such as piceatennol and scirpusin B (a dimer of the prior), which have an important antioxidant function [18] [19], due to the dose-dependent up-regulation of a relevant reduction system, glutathione. In addition, besides inhibiting matrix-metalloproteinase 1 [20], activated by UVB light and responsible for collagen degeneration in skin-aging, they also stimulate collagen synthesis and inhibit melanogenesis [21]. These results strongly suggest that the seeds of the passion fruit contain high amounts of natural molecules that may be used as anti-photoaging cosmetic ingredients.

Furthermore, vitamin A is an important constituent of the epidermis, which 
contributes to the correct physiological functioning of the skin, especially it affects surface lipids and increases skin regeneration [22]. Nutritional deficiencies, lack of exposure to sunlight and excessive oxidative stresses can be causes of vitamin A deficiency. Retinol and others compounds derived from vitamin A are widely used in cosmetic therapies to prevent the signs of photoaging. The application of topical 1\% retinol (a vitamin A derivate) [23] has been shown to lead to an increase in fibroblast activity together with a decrease in metalloproteinase, and as a consequence, an increase in collagen synthesis. These findings have also been histologically confirmed by Fisher et al. [24].

Finally, $\alpha$-hydroxy acids ( $\alpha$ HAs) have been widely used in cosmetic products to improve skin damage caused by UV light, having been successfully shown to decrease roughness, solar keratosis, and excessive pigmentation, as well as to increase collagen levels and elastic-fibre density [25] [26] [27]. Products containing HAs generally improve exfoliation and moisturization [28].

\section{Conclusion}

In this study, we tested four cosmetic products combining active natural ingredients, which were intended to prevent and mitigate the most common imperfections of the skin on the face and body. This specific combination is clinically effective and safe, and contributes to the skin surface hydrolipidic film regeneration, reduction of redness and improvement of wrinkle depth.

\section{References}

[1] Das, C. and Olmsted, P.D. (2016) The Physics of Stratum Corneum Lipid Membranes. Philosophical Transactions of the Royal Society. Mathematical, Physical, and Engineering Sciences, 28, 374.

[2] Thiele, J.J., Schroeter, C., Hsieh, S.N., Podda, M. and Packer, L. (2001) The Antioxidant Network of the Stratum Corneum. Current Problems in Dermatology, 29, 26-42.

[3] Capitanio, B., Lora, V., Ludovici, M., Sinagra, J.L., Ottaviani, M., Mastrofrancesco, A., et al. (2014) Modulation of Sebum Oxidation and Interleukin-1 $\alpha$ Levels Associates with Clinical Improvement of Mild Comedonal Acne. Journal of the European Academy of Dermatology and Venereology, 28, 1792-1797. https://doi.org/10.1111/jdv.12431

[4] Rawlings, A.V. and Harding, C.R. (2004) Moisturization and Skin Barrier Function. Dermatologic Therapy, 17, 43-48. https://doi.org/10.1111/j.1396-0296.2004.04S1005.x

[5] Holck, D.E. and Ng, J.D. (2003) Facial Skin Rejuvenation. Current Opinion in Ophthalmology, 14, 246-252. https://doi.org/10.1097/00055735-200310000-00004

[6] Fulton, J.E. and Porumb, S. (2004) Chemical Peels: Their Place within the Range of Resurfacing Techniques. American Journal of Clinical Dermatology, 5, 179-187. https://doi.org/10.2165/00128071-200405030-00006

[7] Kottner, J., Lichterfeld, A. and Blume-Peytavi, U. (2013) Transepidermal Water Loss in Young and Aged Healthy Humans: A Systematic Review and Meta-Analysis. Archives of Dermatological Research, 305, 315-323. https://doi.org/10.1007/s00403-012-1313-6

[8] Thornton, M.J. (2016) Human Skin: A Mirror for Estrogen Action? Menopause, 23, 
119-120. https://doi.org/10.1097/GME.0000000000000589

[9] Crowther, J.M., Sieg, A., Blenkiron, P., Marcott, C., Matts, P.J., Kaczvinsky, J.R., et al. (2008) Measuring the Effects of Topical Moisturizers on Changes in Stratum Corneum Thickness, Water Gradients and Hydration in Vivo. British Journal of Dermatology, 159, 567-577.

[10] Fujimura, T., Shimotoyodome, Y., Nishijima, T., Sugata, K., Taguchi, H. and Moriwaki, S. (2016) Changes in Hydration of the Stratum Corneum Are the Most Suitable Indicator to Evaluate the Irritation of Surfactants on the Skin. Skin Research and Technology, 23, 97-103. https://doi.org/10.1111/srt.12307

[11] Berardesca, E., Farage, M. and Maibach, H. (2013) Sensitive Skin: An Overview. International Journal of Cosmetic Science, 35, 2-8. https://doi.org/10.1111/j.1468-2494.2012.00754.x

[12] Wan, D.C., Wong, V.W., Longaker, M.T., Yang, G.P. and Wei, F.C. (2014) Moisturizing Different Racial Skin Types. The Journal of Clinical and Aesthetic Dermatology, 7, 25-32.

[13] Shoshani, D., Markovitz, E., Monstrey, S.J. and Narins, D.J. (2008) The Modified Fitzpatrick Wrinkle Scale: A Clinical Validated Measurement Tool for Nasolabial Wrinkle Severity Assessment. Dermatologic Surgery, 34, S85-S91.

[14] Montanher, A.B., Zucolotto, S.M., Schenkel, E.P. and Fröde, T.S. (2007) Evidence of Anti-Inflammatory Effects of Passiflora edulis in an Inflammation Model. Journal of Ethnopharmacology, 109, 281-288. https://doi.org/10.1016/j.jep.2006.07.031

[15] Vargas, A.J., Geremias, D.S., Provensi, G., Fornari, P.E., Reginatto, F.H., Gosmann, G., et al. (2007) Passiflora alata and Passiflora edulis Spraydried Aqueous Extracts Inhibit Inflammation in Mouse Model of Pleurisy. Fitoterapia, 78, 112-119. https://doi.org/10.1016/j.fitote.2006.09.030

[16] Barbosa, P.R., Valvassori, S.S., Bordignon, C.L.J., Kappel, V.D., Martins, M.R., Gavioli, E.C., et al. (2008) The Aqueous Extracts of Passiflora alata and Passiflora edulis Reduce Anxiety-Related Behaviors without Affecting Memory Process in Rats. Journal of Medicinal Food, 11, 282-288. https://doi.org/10.1089/jmf.2007.722

[17] Coleta, M., Batista, M.T., Campos, M.G., Carvalho, R., Cotrim, M.D., Lima, T.C., et al. (2006) Neuropharmacological Evaluation of the Putative Anxiolytic Effects of Passifloraedulis Sims, Its Subfractions and Flavonoid Constituents. Phytotherapy Research, 20, 1067-1073. https://doi.org/10.1002/ptr.1997

[18] Matsui, Y., Sugiyama, K., Kamei, M., Takahashi, T., Suzuki, T., Katagata, Y., et al. (2010) Extract of Passion Fruit (Passiflora edulis) Seed Containing High Amounts of Piceatannol Inhibits Melanogenesis and Promotes Collagen Synthesis. Journal of Agricultural and Food Chemistry, 58, 11112-11118. https://doi.org/10.1021/jf102650d

[19] Sano, S., Sugiyama, K., Ito, T., Katano, Y. and Ishihata, A. (2011) Identification of the Strong Vasorelaxing Substance Scirpusin B, a Dimer of Piceatannol, from Passionfruit (Passiflora edulis) Seeds. Journal of Agricultural and Food Chemistry, 59, 6209-6213. https://doi.org/10.1021/jf104959t

[20] Kim, S., Kim, Y., Lee, Y. and Chung, J.H. (2008) Ceramide Accelerates Ultraviolet-Induced MMP-1 Expression through JAK1/STAT-1 Pathway in Cultured Human Dermal Fibroblasts. Journal of Lipid Research, 49, 2571-2581. https://doi.org/10.1194/jlr.M800112-JLR200

[21] Yokozawa, T. and Kim, Y.J. (2007) Piceatannol Inhibits Melanogenesis by Its Antioxidative Actions. Biological and Pharmaceutical Bulletin, 30, 2007-2011. https://doi.org/10.1248/bpb.30.2007

[22] Wójcik, A., Bartnicka, E., Namieciński, P. and Rotsztejn, H. (2015) Influence of the 
Complex of Retinol-Vitamin C on Skin Surface Lipids. Journal of Cosmetic Dermatology, 14, 92-99. https://doi.org/10.1111/jocd.12140

[23] Varani, J., Warner, R.L., Gharaee-Kermani, M., Phan, S.H., Kang, S., Chung, J.H., et al. (2010) Vitamin A Antagonizes Decreased Cell Growth and Elevated Collagen Degrading Matrix Metalloproteinases and Stimulates Collagen Accumulation in Naturally Aged Human Skin. Journal of Investigative Dermatology, 114, 480-486. https://doi.org/10.1046/j.1523-1747.2000.00902.x

[24] Fisher, G.J., Datta, S.C., Talwar, H.S., Wang, Z.Q., Varani, J., Kang, S., et al. (1996) Molecular Basis of Sun-Induced Premature Skin Ageing and Retinoid Antagonism. Nature, 379, 335-339. https://doi.org/10.1038/379335a0

[25] Van Scott, E.J. and Yu, R.J. (1974) Control of Keratinization with Alpha-Hydroxy Acids and Related Compounds. I. Topical Treatment of Ichthyotic Disorders. Archives of Dermatological Research, 110, 586-590. https://doi.org/10.1001/archderm.1974.01630100046011

[26] Yu, R.J. and Van Scott, E.J. (2004) Alpha-Hydroxyacids and Carboxylic Acids. Journal of Cosmetic Dermatology, 3, 76-87. https://doi.org/10.1111/j.1473-2130.2004.00059.x

[27] Green, B.A. and Briden, E. (2009) PHAs and Bionic Acids: Next Generation of Hydroxy Acids. Cosmeceuticals, 209-215.

[28] Green, B. (2005) After 30 Years ... the Future of Hydroxyacids. Journal of Cosmetic Dermatology, 4, 44-45. https://doi.org/10.1111/j.1473-2165.2005.00159.x

Submit or recommend next manuscript to SCIRP and we will provide best service for you:

Accepting pre-submission inquiries through Email, Facebook, LinkedIn, Twitter, etc. A wide selection of journals (inclusive of 9 subjects, more than 200 journals)

Providing 24-hour high-quality service

User-friendly online submission system

Fair and swift peer-review system

Efficient typesetting and proofreading procedure

Display of the result of downloads and visits, as well as the number of cited articles

Maximum dissemination of your research work

Submit your manuscript at: http://papersubmission.scirp.org/

Or contact jcdsa@scirp.org 